\title{
Increasing Students' Reading Comprehension through Students' Reading Habit
}

\author{
Agustina Ramadhianti ${ }^{1}$, Mesagus Muhammad Sesar Aby Putra ${ }^{2}$, \\ \{agustinaramadhianti79@gmail.com ${ }^{1}$, abbyinside@gmail.com ${ }^{2}$ \} \\ Universitas Indraprasta PGRI, Jakarta, Indonesia ${ }^{12}$
}

\begin{abstract}
Reading is one of the fundamental skills in gaining knowledge. Based on PISA data for 2018 , the reading ability of students in Indonesia was in the bottom five positions. Several factors can determine success in reading comprehension, including reading habits. The research objective was to determine the correlation between reading habits and reading comprehension skills in students. The research method used was descriptive quantitative and correlation studies involving 30 respondents from class X of SMAN 1 Klapanunggal academic year 2019/2020. The data were obtained from the results of questionnaires about reading habits and reading comprehension tests which were processed using regression analysis and correlation analysis. The research findings indicate a positive and significant correlation between reading habits and reading comprehension. Thus, the better the reading habits of the students, the better the reading comprehension skills of the students.
\end{abstract}

Keywords: correlation analysis, reading comprehension, reading habit

\section{Peningkatan Pemahaman Membaca Siswa melalui Kebiasaan Membaca Siswa}

\begin{abstract}
Abstrak. Membaca merupakan salah satu keterampilan mendasar dalam memperoleh pengetahuan. Berdasarkan data PISA tahun 2018, kemampuan membaca siswa di Indonesia berada di posisi lima terbawah. Beberapa faktor dapat menentukan keberhasilan dalam pemahaman membaca, diantaranya adalah kebiasaan membaca. Tujuan penelitian adalah untuk mengetahui korelasi antara kebiasaan membaca dan keterampilan pemahaman membaca pada siswa. Metode penelitian yang digunakan adalah deskriptif kuantitatif dan studi korelasi dengan melibatkan 30 responden yang berasal dari siswa kelas X SMAN 1 Klapanunggal tahun akademik 2019/2020. Data diperoleh dari hasil kuesioner tentang kebiasaan membaca dan tes pemahaman membaca yang diolah menggunakan analisis regresi dan analisis korelasi. Temuan penelitian menunjukkan adanya korelasi positif dan signifikan antara kebiasaan membaca dengan pemahaman membaca. Dengan demikian, semakin baik kebiasaan membaca siswa, maka akan semakin baik pula keterampilan pemahaman membaca siswa.
\end{abstract}

Kata kunci: analisis korelasi, kebiasaan membaca, pemahaman membaca

\section{Pendahuluan}

Dalam dunia pendidikan, pemerolehan ilmu pengetahuan merupakan salah satu proses dalam menentukan keberhasilan sebuah pembelajaran. Ilmu pengetahuan didapat dengan 
berbagai cara, dan salah satunya adalah melalui keterampilan berbahasa. Ada empat keterampilan dalam berbahasa yaitu berbicara, menyimak, membaca, dan menulis. Di antara keempat keterampilan tersebut, membaca merupakan keterampilan yang memegang peran penting dalam proses pembelajaran. Dengan membaca, seseorang bisa memperoleh informasi yang diperlukan untuk memahami ilmu pengetahuan. Membaca menjadi hal yang penting karena dua alasan yaitu selain memberikan kontribusi bagi siswa itu sendiri dalam menunjang pendidikan ke jenjang berikutnya, membaca juga memberikan dampak positif dalam meningkatkan pengetahuan kosakata untuk penguasaan bahasa [1].

Berdasarkan data PISA 2018, Indonesia berada pada posisi 74 dari 79 negara dalam kemampuan membaca yang dimiliki para siswa [2]. Tentunya keadaan ini menjadi perhatian penting di saat kemajuan teknologi semakin meningkat. Oleh karena itu, pada abad 21 ini, dunia pendidikan harus mempersiapkan siswa agar dapat menyesuaikan diri terhadap perubahan sosial dan teknologi yang belum pernah terjadi sebelumnya, di mana membaca merupakan sumber bagi keberlanjutan sebuah pendidikan [3].

Definisi dari membaca adalah proses dalam penerimaan bahasa yang melibatkan pengenalan, penafsiran dan daya pemahaman dalam sebuah bacaan [4]. Dalam membaca diperlukan suatu keterampilan untuk memahami isi bacaan baik secara menyeluruh maupun terperinci, dan keterampilan ini disebut sebagai pemahaman membaca. Sejatinya tujuan membaca adalah untuk memperoleh informasi dari sebuah teks. Informasi yang didapat adalah hasil memahami isi bacaan berdasarkan persepsi pembaca terhadap sebuah tulisan, dengan membandingkan informasi dalam tulisan terhadap pengetahuan yang dimiliki pembaca. Beberapa keterampilan dalam membaca antara lain mengenal kata-kata, mengidentifikasi fungsi tata bahasa, memperhatikan informasi secara rinci, membandingkan, menyimpulkan, dan membuat perkiraan terhadap isi bacaan [5]. Hal ini penting, bahwasanya membaca sebagai suatu keterampilan yang dapat mendukung peningkatan akademik siswa dengan cara menganalisis, menjelaskan dan mengungkapkan ide-ide siswa terhadap bahan bacaan [6].

Banyak faktor yang terlibat di dalam meningkatkan pemahaman membaca bagi para siswa. Salah satu faktornya adalah strategi guru dalam mengajar. Penting bagi guru untuk memilih strategi membaca yang tepat agar siswa dapat memahami materi pelajaran melalui bacaan. Jika guru memberikan strategi membaca yang sesuai bagi para siswanya, maka siswa akan dapat meningkatkan kemampuannya dalam memahami pelajaran [7]. Selain itu ada juga faktor dari dalam diri siswa itu sendiri, diantaranya adalah motivasi dalam membaca. Hasil penelitian menunjukkan bahwa motivasi dalam membaca memberikan pengaruh positif terhadap kegiatan membaca [8]. Dengan memiliki motivasi membaca yang tinggi, maka akan tinggi pula keinginan siswa untuk banyak membaca, dan nantinya bisa berdampak positif pada keterampilan dalam pemahaman bacaan.

Mengingat pentingnya pemahaman membaca dalam setiap proses perolehan pengetahuan secara tertulis, maka keterampilan membaca pemahaman ini harus dapat dioptimalkan. Terutama mulai dibangun dari dalam diri setiap siswa. Salah satu cara yang bisa digunakan adalah membangun kebiasaan membaca. Kebiasaan membaca dapat distimulasi oleh pengajar, di mana pengajar sebaiknya tidak selalu memberikan catatan melainkan mendorong siswa untuk mencari sendiri informasi dengan membacanya sebagai bahan telaah [9]. Kebiasaan membaca merupakan sarana yang penting dalam mengembangkan mental dan kepribadian seseorang untuk dapat berbaur dari segi sosial dan ekonomi serta dalam kehidupan berbangsa [10]. Seseorang yang banyak membaca akan memperoleh banyak informasi yang bisa bermanfaat di dalam pergaulannya. Banyak jenis bacaan yang bisa dipilih sesuai dengan kebutuhan dan keinginan. Dapat dikatakan kebiasaan membaca juga merupakan suatu perilaku yang menjadikan membaca adalah kegemaran dan berkaitan dengan selera bacaan pada setiap 
individu [11]. Kebiasaan membaca yang baik dan positif memiliki peran penting dalam meningkatkan keterampilan pemahaman membaca.Tanpa memiliki kebiasaan membaca seseorang akan mengalami kesulitan dalam pembelajaran terutama yang berkaitan dengan materi bacaan, karena bisa saja seseorang menganggap membaca itu tidaklah menyenangkan. Sebuah penelitian menemukan bahwa dengan menjadikan kebiasaan membaca adalah hal yang menyenangkan maka akan dapat meningkatkan pencapaian hasil belajar di sekolah [12].

Menjadikan kegiatan membaca sebagai suatu kebiasaan tidaklah terjadi dalam waktu yang singkat. Oleh karena itu, kebiasaan membaca dimulai dari bagian yang terdekat dari siswa, yaitu keluarga dan lingkungannya. Siswa cenderung memiliki keinginan untuk membaca bila dipengaruhi oleh peran guru di sekolah, peran orang tua di rumah, teman-teman sebaya dan juga sikap seseorang terhadap kegiatan membaca [13]. Biasanya seorang siswa akan memiliki ketertarikan dalam membaca bila orang tuanya selalu menerapkan kegiatan membaca dan menyediakan bahan bacaan yang bervariasi. Guru di sekolah juga membiasakan siswa untuk mencari sendiri informasi yang diperlukan, sehingga akan tercipta suasana yang kondusif dalam pembelajaran. Bahkan hal ini masih berlanjut ketika seseorang sudah menjadi mahasiswa, sebagaimana hasil penelitian yang membuktikan bahwa kebiasaan membaca para mahasiswa di tingkat pertama didorong oleh peran orang tua dan guru [14].

Berdasarkan uraian tersebut maka penelitian ini bertujuan untuk mengetahui bagaimana hubungan antara kebiasaan membaca dan pemahaman membaca siswa SMAN $\mathrm{X}$ Klapanunggal.

\section{Metode}

Metode yang digunakan adalah deskriptif kuantitatif dengan studi korelasional. Terdapat dua variabel dalam penelitian ini yaitu kebiasaan membaca siswa sebagai variabel bebas, dan pemahaman membaca siswa sebagai variabel terikat. Adapun jumlah responden adalah 30 siswa yang diambil menggunakan teknik probability sampling yaitu sampel memiliki peluang yang sama dari bagian populasi [15].

Instrumen yang digunakan dalam pengambilan data adalah angket kebiasaan membaca siswa dan tes pemahaman membaca pada siswa yang sudah melalui uji validitas dan reliabilitas instrumen. Indikator dalam angket kebiasaan membaca yaitu seberapa sering siswa membaca, berapa banyak bacaan yang dibaca dan jenis bacaan apa yang dibaca oleh siswa [16]. Sedangkan untuk memperoleh data pada pemahaman membaca siswa, instrumen yang digunakan adalah tes pemahaman membaca di mana lebih menekankan pada pemahaman dalam menentukan ide pokok paragraf, menentukan informasi baik yang tersurat maupun tersirat [17]. Jumlah pertanyaan pada instrumen kebiasaan membaca sebanyak 24 buah dengan nilai maksimum adalah 96, dan untuk instrumen pemahaman membaca sebanyak 25 soal dengan nilai maksimum adalah 100 .

Setelah data diperoleh maka data akan dianalisis untuk menguji normalitasnya dengan menggunakan rumus Liliefors, mengacu pada ketentuan, data akan dikatakan berdistribusi normal jika nilai $\mathrm{Lo}_{\text {hitung }}$ lebih rendah dari nilai $\mathrm{Lo}_{\text {tabel }}$ Tabel dan uji linearitas menggunakan analisis varian. Kemudian untuk menguji hipotesis mengenai ada tidaknya hubungan antara dua variabel, dilakukan dengan mencari koefisien korelasi berdasarkan rumus Pearson Product Moment. Perhitungan selanjutnya yaitu mencari koefisien determinasi untuk mengetahui sejauh mana kebiasaan membaca memberikan kontribusi terhadap pemahaman membaca, serta uji keberartian atau signifikansi hubungan antara kedua variabel tersebut 
dengan menggunakan rumus uji t.

\section{Hasil dan Pembahasan}

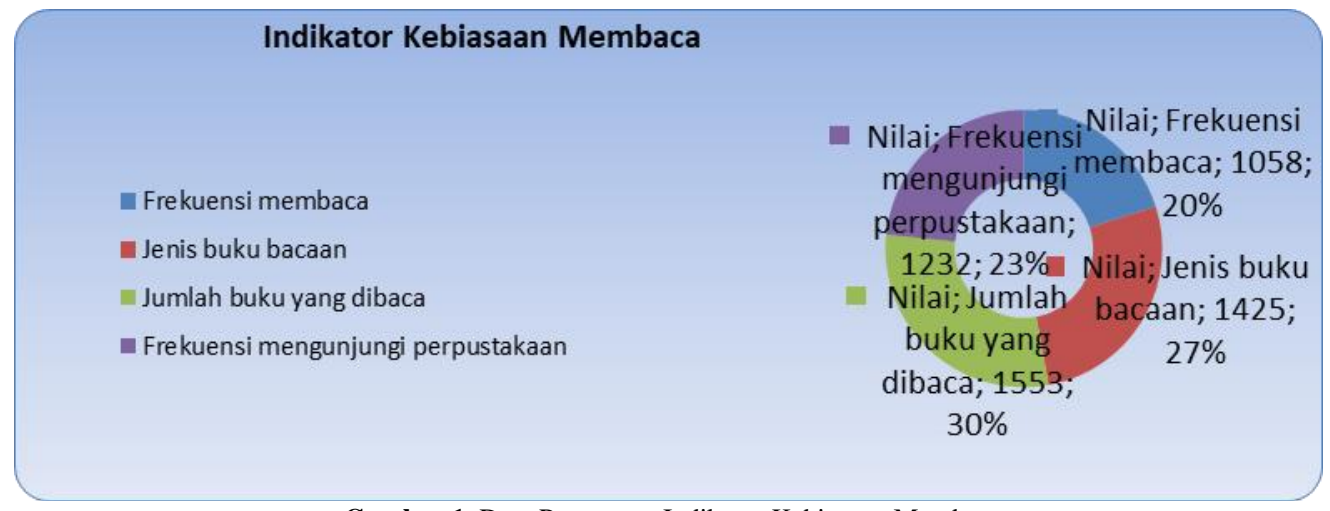

Gambar 1. Data Persentase Indikator Kebiasaan Membaca

Berdasarkan definisi dari beberapa ahli, kebiasaan membaca adalah suatu kegiatan berulang mengenai seberapa sering seseorang membaca, jenis buku yang dibaca, banyaknya buku yang dibaca atau seberapa sering seseorang mengunjungi perpustakaan untuk mendapatkan materi bacaan. Hasil perhitungan dari angket kebiasaan membaca yang diberikan kepada 30 siswa SMA N 1 Klapanunggal dapat dilihat pada gambar 1. Persentase tertinggi untuk indikator kebiasaan membaca ada pada indikator jumlah buku yang dibaca sebesar 30\%, diikuti oleh jenis buku bacaan sebesar 27\%. Sementara itu frekuensi mengunjungi perpustakaan memperoleh nilai sebesar $23 \%$, dan yang terendah adalah frekuensi membaca yaitu sebesar 20\%. Hal ini menunjukkan bahwa siswa SMA N 1 Klapanunggal lebih memaknai kebiasaan membaca berdasarkan dengan jumlah buku yang dibaca. Semakin banyak buku yang dibaca, akan semakin sering frekuensi kegiatan membaca sehingga kebiasaan membaca akan tercipta.

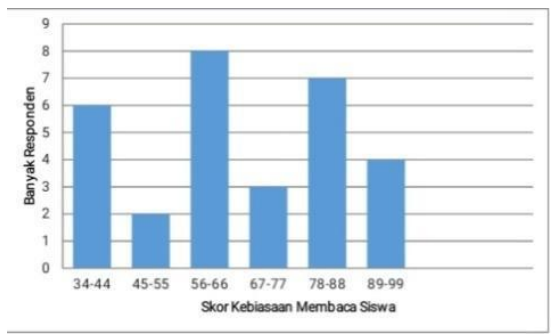

Gambar 2. Data Kebiasaan Membaca

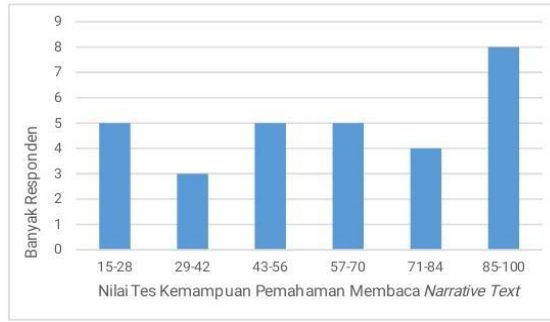

Gambar 3. Data Pemahaman Membaca

Selanjutnya pada gambar 2 menampilkan data hasil nilai angket kebiasaan membaca dari setiap siswa. Dari data tersebut, diketahui sebanyak 6 siswa mendapat nilai dengan rentang terendah (34-44); 2 siswa berada pada rentang 44-45 ; 8 siswa berada pada range 56-66; 3 
siswa menempati rentang 66-77; 7 siswa berada pada posisi rentang 77-88 dan 4 siswa memperoleh nilai pada rentang tertinggi (89-99). Nilai rata-rata untuk data kebiasaan membaca sebesar 65,8 dan hal ini menunjukkan kebiasaan membaca siswa SMA N 1 Klapanunggal masih tergolong cukup.

Gambar 3 menyajikan data nilai pemahaman membaca . Dari data tersebut diketahui sebanyak 5 siswa berada pada rentang terendah (15-28); 3 siswa berada pada rentang (29-42); 5 siswa berada pada rentang (43-56); 5 siswa juga berada pada rentang (57-70); 4 siswa berada pada rentang (71-84) dan sebanyak 8 siswa memperoleh nilai pada rentang tertinggi (85-100). Nilai rata-rata pada data pemahaman membaca adalah 62,2 dan termasuk dalam kategori sedang.

Setelah mendapatkan deskripsi data tersebut, dilanjutkan dengan uji normalitas data. Dengan menggunakan rumus Liliefors untuk $n=30$ dan $\alpha=0,05$ dihasilkan nilai Lotabel $=0,162$. Untuk data kebiasaan membaca siswa diperoleh nilai Lo hitung sebesar 0,088, sementara nilai Lohitung untuk data pemahaman membaca siswa adalah 0,120. Terlihat hasil Lohitung, baik dari data kebiasaan membaca maupun data pemahaman membaca menunjukkan nilai lebih kecil

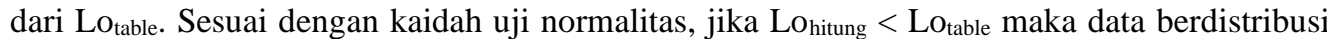
normal.

Tabel 1. Linearitas Kebiasaan Membaca terhadap Pemahaman Membaca

\begin{tabular}{|c|c|c|c|c|c|c|c|}
\hline \multicolumn{8}{|c|}{ ANOVA Table } \\
\hline & & & $\begin{array}{l}\text { Sum of } \\
\text { Squares }\end{array}$ & df & $\begin{array}{l}\text { Mean } \\
\text { Square }\end{array}$ & $\mathrm{F}$ & Sig. \\
\hline \multirow{5}{*}{$\begin{array}{l}\text { Pemahaman } \\
\text { Membaca * } \\
\text { Kebiasaan } \\
\text { membaca }\end{array}$} & \multirow{3}{*}{$\begin{array}{l}\text { Between } \\
\text { Groups }\end{array}$} & (Combined) & 14342.500 & 23 & 623.587 & .635 & .800 \\
\hline & & Linearity & 8071.186 & 1 & 8071.186 & 8.220 & .029 \\
\hline & & $\begin{array}{l}\text { Deviation from } \\
\text { Linearity }\end{array}$ & 6271.314 & 22 & 285.060 & .290 & .985 \\
\hline & \multicolumn{2}{|c|}{ Within Groups } & 5891.667 & 6 & 981.944 & & \\
\hline & \multicolumn{2}{|l|}{ Total } & 20234.167 & 29 & & & \\
\hline
\end{tabular}

Selanjutnya untuk uji linearitas menggunakan perhitungan uji $\mathrm{F}$, berdasarkan jumlah data yang ada maka didapat nilai $\mathrm{F}_{\text {tabel }}=3,67$ sedangkan dari hasil perhitungan data pada tabel 1 diperoleh nilai $F_{\text {hitung }}=0,290$. Karena $F_{\text {hitung }}$ lebih kecil dari $F_{\text {tabel }}$ maka kedua variabel tersebut dikatakan linear. Jika kedua variabel tersebut linear maka dapat dicari persamaan regresinya.

Tabel 2. Koefisien Regresi Kebiasaan Membaca dan Pemahaman Membaca

\begin{tabular}{|c|c|c|c|c|c|c|}
\hline \multirow[b]{3}{*}{ Model } & \multicolumn{6}{|c|}{ Coefficients $^{a}$} \\
\hline & & \multicolumn{2}{|c|}{ Unstandardized Coefficients } & \multirow{2}{*}{$\begin{array}{c}\text { Standardized } \\
\text { Coefficients } \\
\text { Beta } \\
\end{array}$} & \multirow[b]{2}{*}{$t$} & \multirow[b]{2}{*}{ Sig. } \\
\hline & & B & Std. Error & & & \\
\hline \multirow[t]{2}{*}{$\overline{1}$} & (Constant) & 4.833 & 13.835 & & .349 & .729 \\
\hline & Kebiasaan membaca & .871 & .202 & .632 & 4.311 & .000 \\
\hline
\end{tabular}

a. Dependent Variable: Pemahaman Membaca

Adapun persamaan regresi yang diperoleh berdasarkan tabel 2 adalah: $\hat{\mathrm{Y}}=4,833+$ $0,871 \mathrm{X}$ 
Persamaan ini memiliki arti bahwa setiap perubahan nilai variabel kebiasaan membaca sebesar satu satuan akan mempengaruhi nilai variabel pemahaman membaca sebesar 0,871 satuan. Persamaan regresi ini memiliki hubungan yang positif karena koefisien kebiasaan membaca bernilai positif. Hal ini bermakna semakin meningkatnya kebiasaan membaca maka akan kemampuan pemahaman membaca akan meningkat pula.

Tabel 3. Koefisien Korelasi Kebiasaan Membaca dengan Pemahaman

Membaca

Model Summary

\begin{tabular}{llccr}
\hline Model & $\mathrm{R}$ & $\mathrm{R}$ Square & $\begin{array}{c}\text { Adjusted R } \\
\text { Square }\end{array}$ & $\begin{array}{c}\text { Std. Error of the } \\
\text { Estimate }\end{array}$ \\
\hline 1 & $.632^{\mathrm{a}}$ & .399 & .377 & 20.842 \\
\hline a. Predictors: (Constant), Kebiasaan membaca & & &
\end{tabular}

Untuk melihat bagaimana korelasi antara variabel kebiasaan membaca dengan variabel pemahaman membaca maka dilakukan uji Pearson Product Moment . Dari hasil perhitungan pada tabel 3, diperoleh nilai $r_{\text {hitung }}$ sebesar 0,632 sementara nilai $r_{\text {tabel }}=0,361$. Karena nilai $\mathrm{r}_{\text {hitung }}$ lebih besar dari nilai $\mathrm{r}_{\text {tabel }}$ maka dapat disimpulkan bahwa terdapat korelasi antara kebiasaan membaca dengan pemahaman membaca dalam kategori kuat. Dengan nilai r sebesar 0,632 diperoleh nilai koefisien determinasi sebesar 0,399. Dengan demikian kebiasaan membaca memberikan kontribusi sebesar 39,9\% terhadap keterampilan pemahaman membaca, sementara sisanya diberikan oleh faktor lainnya. Hal ini sejalan dengan hasil penelitian tahun 2018 yang menggambarkan bahwa kebiasaan membaca memberikan kontribusi sebesar 51,8 $\%$ terhadap literasi sains pada siswa SMA [18]. Ternyata kebiasaan membaca juga memiliki dampak di berbagai bidang ilmu.

Analisis yang terakhir adalah uji keberartian atau signifikansi dari korelasi tersebut melalui uji t dengan nilai $t_{\text {tabel }}$ ditentukan berdasarkan $\mathrm{a}=0,05$ uji dua pihak dengan $\mathrm{dk}=\mathrm{n}-2$ .Sesuai jumlah data dengan $\mathrm{dk}=28$ diperoleh nilai $\mathrm{t}_{\text {tabel }}=2,048$. Masih berdasarkan tabel 2, didapat nilai $t_{\text {hitung }}$ adalah 4,331. Jika dibandingkan dengan $t_{\text {tabel }}$ maka nilai $t_{\text {hitung }}$ lebih besar sehingga dapat disimpulkan bahwa korelasi antara kebiasaan membaca dengan pemahaman membaca adalah signifikan. Dengan $a=0,05$ menandakan jika hubungan antara kebiasaan membaca dengan membaca pemahaman memiliki keberartian sebesar 95\%. Hal ini sejalan dengan hasil penelitian pada siswa kelas X di sebuah SMK di Jakarta, bahwa kebiasaan membaca memiliki pengaruh yang signifikan pada pemahaman membaca dengan pembuktian , nilai $t_{\text {hitung }}=3,305$ di mana nilai ini lebih besar dari nilai $t_{\text {tabel }}=1,99$ [19]. Dari hasil uji hipotesis dan analisis data menunjukkan bahwa terdapat korelasi yang positif dan signifikan antara kebiasaan membaca dan pemahaman membaca. Semakin baik kebiasaan membaca dilakukan maka akan semakin baik pula hasil pemahaman dalam membaca. Tingkat kebiasaan membaca seseorang bisa dilihat dari jumlah dan jenis buku yang dibaca, seberapa sering seseorang menggunakan waktunya untuk membaca atau mengunjungi perpustakaan. Jika kebiasaan membaca dapat dijadikan sebagai suatu kegemaran maka hal ini akan sangat memberi manfaat bagi keberhasilan terutama dalam bidang pendidikan.

\section{Simpulan}

Berdasarkan hasil dan pembahasan dapat disimpulkan bahwa antara kebiasaan membaca dan pemahaman membaca pada siswa kelas X di SMAN Klapanunggal memiliki hubungan 
yang positif dan signifikan. Kebiasaan membaca yang baik memiliki keberartian yang besar terhadap peningkatan pemahaman membaca, Kebiasaan membaca juga memberi pengaruh pada cakupan yang lebih luas lagi yaitu terhadap hasil belajar, sehingga disarankan bagi siswa untuk banyak membaca dari berbagai sumber guna mencari pengetahuan secara mandiri daripada selalu diberikan oleh pengajar.

Mengingat adanya hubungan yang kuat dan positif antara kebiasaan membaca pemahaman membaca, maka perlu kiranya bagi para pendidik dan orang tua untuk mengupayakan kebiasaan membaca bagi para siswa. Pihak orang tua maupun pihak sekolah agar dapat menyediakan banyak buku bacaan dengan berbagai jenis pengetahuan dan juga tempat yang kondusif untuk membaca. Kebiasaan adalah hal yang harus dilakukan secara berulang dalam durasi yang lama sehingga perlu dipupuk sejak dini. Semoga hasil dari pembahasan ini dapat dijadikan pertimbangan untuk dapat meningkatkan pemahaman membaca siswa melalui kebiasaan membaca yang baik sehingga dapat menunjang keberhasilan proses pembelajaran.

\section{Referensi}

[1] Harmer J. How to Teach English (Second Edition). ELT J. 2007;

[2] Tohir M. Hasil PISA Indonesia Tahun 2018. Pap Mat. 2019;

[3] Chettri MK, Rout SK. Reading habits - an overview. IOSR J Humanit Soc Sci. 2013;

[4] Khand Z. Teaching Reading Skills: Problems \& Suggestions. J Res (Faculty Lang Islam Stud. 2004;5:43-56.

[5] Richards JC, Schmidt R. Longman Dictionary of Language Teaching \& Applied Linguistics [Internet]. Proceedings of the 21st Asian Pacific Weed Science Society (APWSS) Conference, 2-6 October 2007, Colombo, Sri Lanka. 2010. 178-185 p. Available from: http://images.pcmac.org/Uploads/JeffersonCountySchools/JeffersonCountySchools/Departments/D ocumentsSubCategories/Documents/English - Dictionary of Language Teaching and Applied Linguistics.pdf

[6] Pourhosein GA, Sabouri NB. How Can Students Improve Their Reading Comprehension Skill? J Stud Educ. 2016;

[7] Küçükoğlu H. Improving Reading Skills Through Effective Reading Strategies. Procedia - Soc Behav Sci. 2013;

[8] Ahmadi MR. The Impact of Motivation on Reading Comprehension. Int J Res English Educ. 2017;

[9] Owusu-Acheaw M, Larson AG. Reading habits among students and its effect on academic performance: A study of students of Koforidua Polytechnic. Libr Philos Pract. 2014;

[10] Clark C, Rumbold K. Reading for pleasure: literature overview. Natl Lit Trust. 2006

[11] Sangkaeo S. Reading habit promotion in ASEAN libraries. In: 65th IFLA Council and General Conference Bangkok, Thailand, August 20 - August 28, 1999. 1999.

[12] Hughes-Hassell S, Rodge P. The Leisure Reading Habits of Urban Adolescents. J Adolesc Adult Lit. 2007;

[13] Huang H-C, Tsai Y-H, Huang S-H. The Relevant Factors in Promoting Reading Activities in Elementary Schools. Int J Eval Res Educ. 2015;4(2):62.

[14] Parlette M, Howard V. Personal Growth, Habits and Understanding: Pleasure Reading Among First-Year University Students. Evid Based Libr Inf Pract. 2010;

[15] Sugiyono. Metode Penelitian Kuantitatif, Kualitatif dan R \& D.Bandung:Alfabeta. Metod Penelit Kuantitatif, Kualitatif dan R DBandungAlfabeta. 2012;

[16] Shen L-B. Computer technology and college students' reading habits. 嘉南學報. 2006;32(32 期: p. 559-572):559-72.

[17] Grabe W, Stoller FL. Teaching reading: sound foundations and effective practices. Teach Res Read. 2002. 
[18] P NAA, Suryanda A, W RD. Hubungan Kebiasaan Membaca Dengan Kemampuan Literasi Sains Siswa Sma Di Jakarta Timur. Bioma J Ilm Biol. 2018;

[19] Siregar RN. Pengaruh Kebiasaan Membaca dan Penguasaan Kosakata terhadap Pemahaman Membaca Siswa (Survei di SMK Jakarta Timur). Deiksis. 2017;9(02):204. 